\title{
Survey Says...?: Assessing Interlibrary Loan/ Document Delivery Use and Awareness for Responsive Service Delivery
}

\author{
Zheng Ye (Lan) Yang, Susan G. Goodwin \& Doug Hahn
}

To cite this article: Zheng Ye (Lan) Yang, Susan G. Goodwin \& Doug Hahn (2020): Survey Says...?: Assessing Interlibrary Loan/Document Delivery Use and Awareness for Responsive Service Delivery, Journal of Interlibrary Loan, Document Delivery \& Electronic Reserve, DOI: 10.1080/1072303X.2020.1752877

To link to this article: https://doi.org/10.1080/1072303X.2020.1752877

Published online: 15 Apr 2020.

Submit your article to this journal $\sqsubset$

Џ Article views: 21

Q View related articles 두

View Crossmark data $₫$ 


\title{
Survey Says ... ?: Assessing Interlibrary Loan/Document Delivery Use and Awareness for Responsive
} Service Delivery

\author{
Zheng Ye (Lan) Yang (D), Susan G. Goodwin, and Doug Hahn \\ Texas A\&M University Libraries, College Station, Texas, USA
}

\begin{abstract}
The object of this study is to assess Texas A\&M University (TAMU) students/faculty/staff members' use and awareness of the Libraries' free document delivery and interlibrary loan service, branded as "Get It For Me." Since 2010, we have continued to see a decline in new user registrations each year. Previous Get It For Me user surveys conducted in 2003 and 2011 indicated that the overall satisfaction of registered users was high and customer feedback gleaned from these surveys was used to initiate a number of service improvements. But what about the large percentage of the campus community who do not use the Get It For Me service? Are they aware of what this service has to offer? If so, why might they choose not to use it? If they are not aware of the service, might they use it if they knew more about how it can assist them in their scholarly endeavors? Instead of only surveying those customers who have used this service, we invited everyone on TAMU College Station campus to participate in the survey. Promoting the service is a vital component of service delivery.
\end{abstract}

\section{KEYWORDS}

Assess of interlibrary loan and document delivery service; awareness of open access resources; customer satisfaction; expected delivery time; format preference; survey

\section{Introduction}

Texas A\&M University (TAMU) Libraries' document delivery and interlibrary loan service, branded as Get It For Me (GIFM), is considered to be "the best service that the Libraries offer," "the best tool ever," and "instrumental for my research" by its users. This free service offered to all of our campus community regardless of their academic status was first launched in the summer of 2002 (Yang, 2005). Since 2010, however, we have continued to see a decline in new user registrations each year. According to ILLiad, our interlibrary loan management database, in 2018, we had 8,619 active users taking advantage of this free service. Given that our campus population is close to 75,000 (including students, faculty, and staff), this suggests that only $11 \%$ are using the GIFM service. Previous Get 
It For Me user surveys conducted in 2003 (Yang, 2004) and 2011 (Yang et al., 2012) indicated that the overall satisfaction of registered users was high and customer feedback gleaned from these surveys was used to initiate a number of service improvements (Yang et al., 2012). But what about the large percentage of the campus community who do not use the GIFM service? Are they aware of what this service has to offer? If so, why might they choose not to use it? If they are not aware of the service, might they use it if they knew more about how it can assist them in their scholarly endeavors?

With these questions in mind, the authors initiated a new Get It For Me survey in the fall of 2019 to reach as broad a user group as possible. The goal of the survey was threefold in nature: (1) to raise greater awareness of GIFM on campus in order to increase registered users of this free and valuable research service, (2) to measure overall user satisfaction of the current customer base, and (3) to solicit valuable feedback from both registered users and non-registered potential users to identify needs and perceptions related to optimal interlibrary loan/document delivery service provision to better inform our next round of service enhancements. As Leykam remarked: "If ILL services continue to rely on current users, it will only serve a select clientele and fall short of its potential" (Leykam, 2008). Promoting the service is a vital component of service delivery. "Many libraries have wonderful services but users are unaware of their availability" (Schmidt, 2007).

\section{Literature review}

A scan of literature reveals that over the years, a number of survey studies have been conducted on customer satisfaction of the interlibrary loan and or document delivery services at different university libraries (AtwaterSinger, 2011; Landes, 2001; Naylor \& Wolfe, 2008; Perrault \& Arseneau, 1995). Some studies targeted specific user groups. Frank and Bothmann assessed undergraduate interlibrary loan use, and their satisfaction and reasons for not using the service (Frank \& Bothmann, 2008). D'Elia and Hutkins surveyed faculty use of document delivery services. They identified differences between users and nonusers, the reasons for nonuse, and the correlates of extent of use (D'Elia \& Hutkins, 1986). Some studies focused on assessing the value of interlibrary loan (ILL) to their customers (Fong, 1997). Little and Leon wrote: "ILL operations must begin to understand the value placed on their services by their patrons." They gathered extensive qualitative feedback, cross-analyzed patron perceptions, satisfaction, and the value placed on resource sharing at three different types of libraries, namely an ARL library, a small private liberal arts library, and a large state 
public library. The authors concluded that speed, access, people, and quality are the four most valued ILL features by their customers (Little \& Leon, 2015). Other service providers have used surveys to investigate the awareness of library services at large (Del Bosque et al., 2017). Lucas called to "market ILL [to users] so that they understand this service provides them with seemingly endless access to resources around the world" (Lucas, 2011). In a information rich world influenced by easy access to materials thanks to search tools like Google, the proliferation of e-commerce sites like Amazon, and an increase in preference for self-service and peer-topeer lending practices, these studies and others like them challenge libraries to rethink ILL in order to stay relevant, survive, and thrive (Jong \& Nance, 2014; Kenefick \& Devito, 2013; Mak, 2012; McGrath, 2012; Muhonen \& Saarti, 2016).

This study is unique because in addition to soliciting traditional survey feedback about the GIFM service from users and nonusers alike, the questions targeted to measure overall service awareness also included an educational component in the form of service summaries to teach self-identified nonusers about GIFM's functions to encourage greater use of this valuable and free research service. The authors will compare their findings with those reported in earlier studies to determine similarities and differences and determine next steps for service enhancements. The survey results will also inform staff from across the library more broadly about user needs across departments and user groups, as well as the different ways in which our customers learn about our services and how these lessons may inform our future activities, particularly in the areas of public services and marketing.

\section{Methodology}

The survey questionnaire consisted of an online instrument administered to and completed by the respondents via Qualtrics survey software which allowed for the anonymity of the respondents. The survey invitation was sent out on October 3, 2019 to every TAMU College Station campus student, faculty, and staff member via the campus Bulk Email system. Participants were asked to voluntarily participate in the study by clicking on a web link included in the email message that directed them to the survey. All questions were optional. Depending on the responses to certain questions, participants invoked logic that would automatically skip to related questions. Within 24 hours after the initial survey invitation, we received 355 responses. A second email reminder was sent approximately two weeks later on October 16. Before a final reminder was sent on October 23, we recorded 728 responses. The survey was closed after 24 days. The total number of responses received after three email invitations 


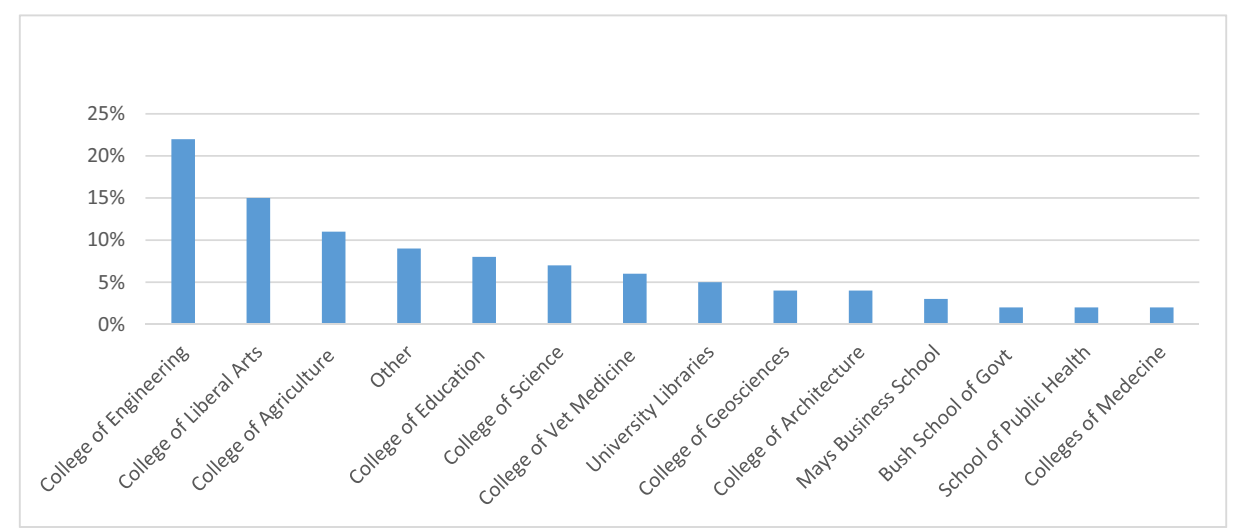

Figure 1. Participants by college affiliation.

was 966, indicating a confidence level of greater than 99\%. According to Qualtrics' website, to reach a confidence level of $99 \%$ for a population size of 75,000, 658 responses are considered ideal, given a 5\% margin of error.

\section{Results}

\section{Demographic information}

Respondents in each status are fairly well represented in this survey, 30\% of the respondents are graduate students, followed by undergraduate students $(24 \%)$, staff $(22 \%)$, faculty $(18 \%)$, and other (6\%). Those marking themselves as "other" clarified their status as retired faculty/staff, research scientist, and lecturer.

Each of TAMU's 14 colleges were represented in the survey with College of Engineering taking the lead, represented by $22 \%$ of the total respondents, followed by respondents from College of Liberal Arts (15\%) and the College of Agriculture \& Life Sciences (11\%). These three colleges in the order reported also happen to be the top three largest colleges on campus by measure of student enrollment. Figure 1 shows the participants by college affiliation. University Libraries employees made up of $5 \%$ of the respondents. Nine percent of participants did not associate with any specific college and instead reported their affiliation to units such as Academic Affairs, Admission and Enrollment, Division of Human Resources, Marketing, Transportation, Student Affairs, and Vice President Office for Research.

\section{Use and awareness of the Get It for Me service}

Texas A\&M University Libraries' Get It For Me service consists of three different service components or functions. We scan chapters/articles from 
Table 1. Respondents' use and awareness of GIFM.

\begin{tabular}{lccc}
\hline Service function & Yes, have used the service & $\begin{array}{c}\text { Aware of the service, but } \\
\text { have not used it }\end{array}$ & $\begin{array}{c}\text { No, not aware of } \\
\text { the service }\end{array}$ \\
\hline $\begin{array}{l}\text { Scan a PDF from our own } \\
\text { collections }\end{array}$ & $56 \%$ & $21 \%$ & $23 \%$ \\
$\begin{array}{c}\text { Book retrieval from } \\
\text { the stacks }\end{array}$ & $48 \%$ & $21 \%$ & $31 \%$ \\
$\begin{array}{l}\text { Borrow from } \\
\text { another library }\end{array}$ & $56 \%$ & $19 \%$ & $25 \%$ \\
\hline
\end{tabular}

our own collections; we retrieve books from our stacks and place a hold for our customers to pick up at their library of choice, or deliver to our faculty/staff members' campus mail box via the campus mail service; and we request items from another library if our copies are checked out or we don't own what our customers need. We asked our participants if they have ever submitted a request to each of these three functions. After each question, an explanation was provided about what the service entails so that those respondents who indicated they were unfamiliar with the service were newly informed. Table 1 displays the respondents' use and awareness of the service.

From the responses, it appears that overall at least two-thirds of survey participants have either used the Get It For Me suite of services or are aware of it. More specifically, scanning and traditional ILL services are roughly tied as the two most used and familiar services with at least threequarters of respondents reporting use or awareness of these services. The book retrieval service is the least used and least familiar component of the GIFM suite of services, used by less than half of the respondents with $31 \%$ reporting they were unaware of this option.

The authors assumed that TAMU Libraries employees who participated in this survey, represented by 48 respondents, would all be aware of the Get It For Me service. Two staff, however, reported that they were not aware of this service; one staff member has been working in the Libraries for over 7 years and the second respondent indicated their tenure at the Libraries between 1 and 3 years.

\section{Users of the service by their home libraries}

For efficiency of service, customers are asked to select their preferred location for pick up during GIFM registration. Customers can choose from four library locations that include Sterling C. Evans Library \& Annex located on main campus and three west campus locations that include the Medical Sciences Library, the Business Library \& Collaboration Commons, and the Policy Sciences \& Economics Library. This registration option ensures that requested items are delivered to a patron's home library for convenient pick up. For our faculty and staff members, they also have the 
Table 2. Use of GIFM service by user type.

\begin{tabular}{lccc}
\hline $\begin{array}{l}\text { Respondent } \\
\text { status }\end{array}$ & $\begin{array}{c}\text { Scan a PDF from } \\
\text { our own collections }\end{array}$ & $\begin{array}{c}\text { Book retrieval } \\
\text { from the stacks }\end{array}$ & $\begin{array}{c}\text { Borrow from } \\
\text { another library }\end{array}$ \\
\hline Graduates & $40 \%$ & $34 \%$ & $37 \%$ \\
Faculty & $29 \%$ & $26 \%$ & $27 \%$ \\
Staff & $14 \%$ & $21 \%$ & $19 \%$ \\
Undergraduates & $11 \%$ & $13 \%$ & $11 \%$ \\
Other & $6 \%$ & $6 \%$ & $6 \%$ \\
\hline
\end{tabular}

option to have requested items delivered to their office mailbox. For our distance education customers, requested items are sent to their home address and come with pre-paid FedEx labels for easy return. Of the respondents who indicated having used the book retrieval service, $80 \%$ indicated their home library to be the main campus library (Evans Library \& Annex), followed by Medical Science Library (11\%), Business Library \& Collaboration Commons (5\%), and the Policy Sciences \& Economics Library (3\%).

\section{Users of the service by status}

Table 2 illustrates the users of each service by status type. Survey responses indicate that graduate students are the top users of the GIFM service with an average of $37 \%$ usage across all three functional categories. Undergraduates use the service the least across all three service functions. This finding is similar with other studies reported, however, TAMU undergraduates' usage of the document delivery/interlibrary loan service comes in even lower. Both Herrera (2003) and Frank and Bothmann (2008) found that faculty usage represented $25 \%$ of requests, staff represented $10 \%$, undergraduate requests fluctuated between 20 to $25 \%$ and graduate requests represented 40 to $46 \%$ of all requests.

\section{Reasons for not using the service}

For those participants who responded they were aware of GIFM services but had not used it, we asked them to share with us why they had not used each specific service function. For each function, we listed several possible reasons for respondents to choose from, including an "other (please specify)" option to allow for free form comments.

When asked to indicate reasons for why they had not used the scan a PDF service, $39 \%$ of respondents selected "I can find all the articles I need myself online" making it the top choice (Figure 2). The second most cited reason specified by respondents was the "other (please specify)" category, where the majority of respondents indicated they either had "no need" or "no need as of yet" to use the scanning service. This finding draws 


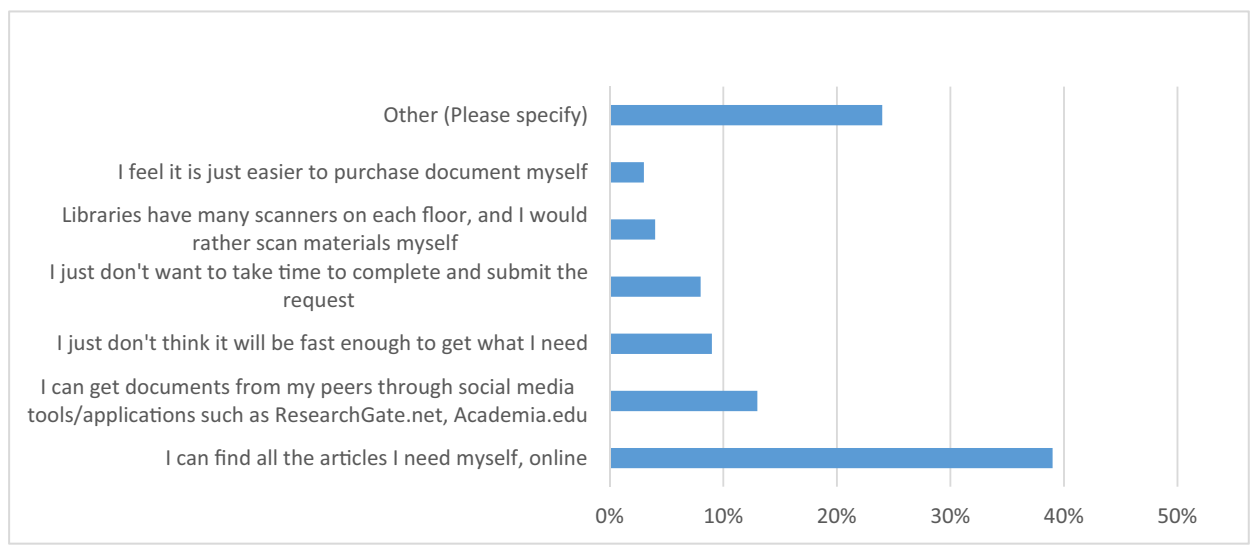

Figure 2. Reasons for not using the scan a PDF from our own collections service function.

similarities with the study conducted by Del Bosque, et al. They reported the top three student reasons for not using library services as: They use Google; they like to do it on their own; and they have no need (Del Bosque et al., 2017).

When asked about reasons for not using the book retrieval function of GIFM, $40 \%$ of respondents indicated "I like to browse the library stacks and get the item myself" making it the top choice for not using the service (Figure 3). This echoes D'Elia and Hutkins' (1986) findings in which they reported the principal reason for nonuse of their document delivery service to be their faculty's preference to browse (D'Elia \& Hutkins, 1986). As illustrated in Figure 3, our respondents also offered several additional reasons for not using the book retrieval service including recurring themes within the second most selected reason of "other (please specify)" category. Here, respondents mostly indicated in free form comments that they either had "no need" or "no need yet" or commented that accessing the stacks themselves was more convenient than the service (e.g., "it is easier to go to the stacks versus filling out a form that might take 2 days").

"TAMU Libraries' collections suit all my needs," selected by $39 \%$ of respondents, came in as the top reason for why respondents had not used GIFM's interlibrary loan service as indicated in Figure 4. Examining the other reasons shared by the respondents, again, a common theme was "no need" or "no need as of yet." Our findings bear similarity with Landes' study. The author reported that "never had the need to use it" was cited as one of the main reasons for not using their interlibrary loan service (Landes, 2001).

We further examined those 290 respondents who stated that they were not aware of this suite of services, as we wanted to find out how long they had been at Texas A\&M University and their status. Data revealed that close to half $(41 \%)$ of the respondents who indicated they were unaware of 


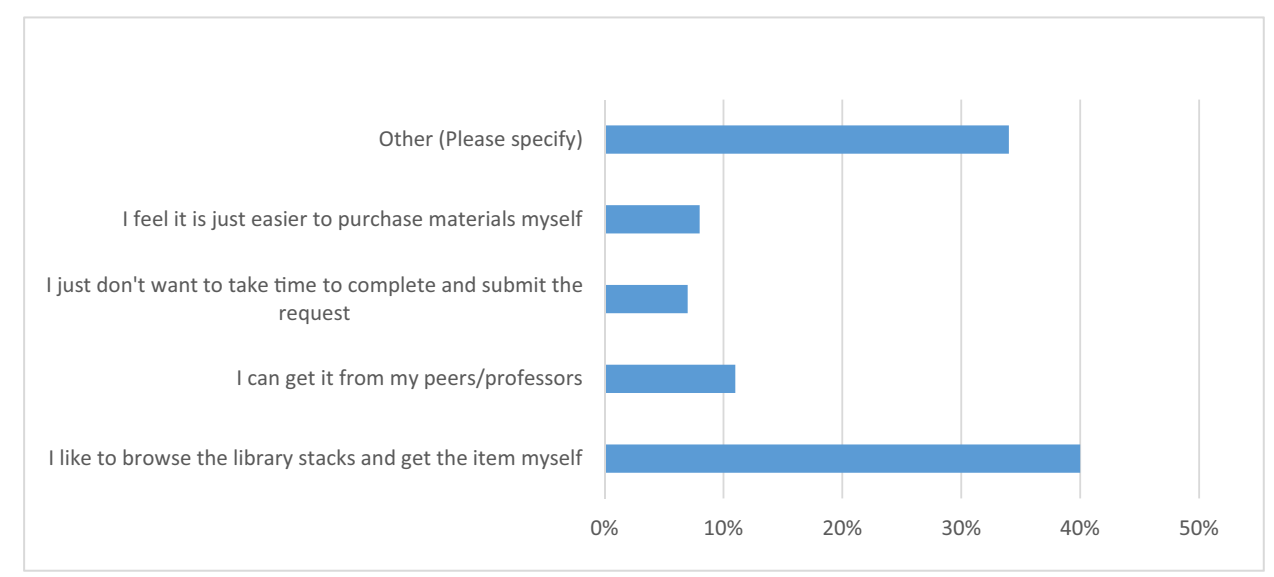

Figure 3. Reasons for not using the book retrieval from the stacks service function.

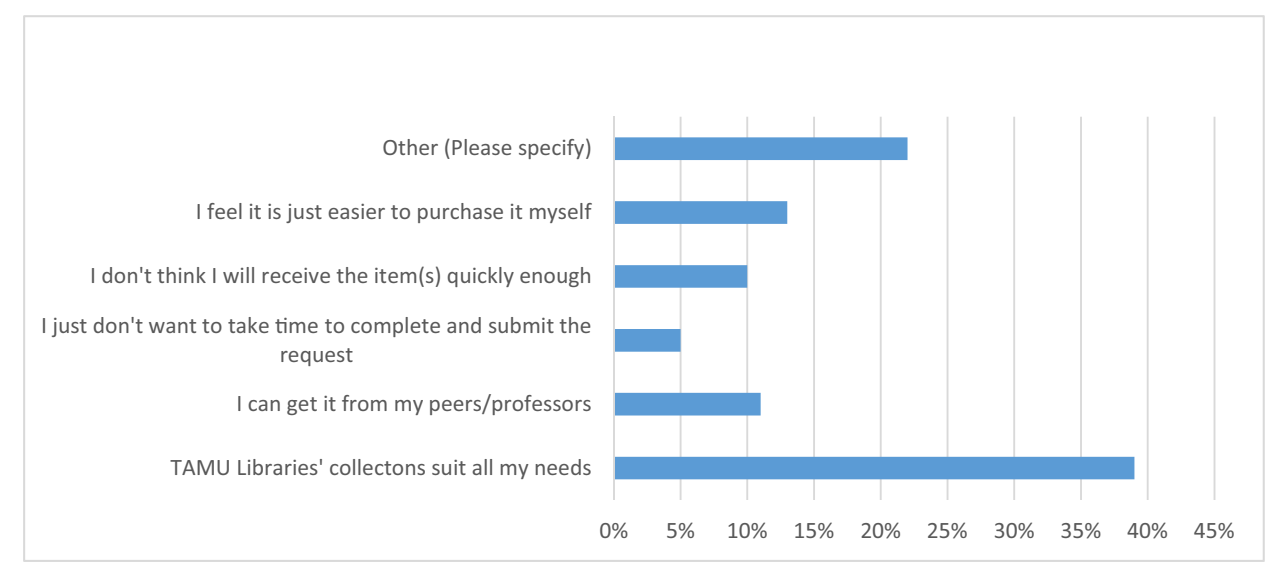

Figure 4. Reasons for not requesting to borrow an item from another library.

GIFM services have only been at TAMU for less than 1 year, another 33\% have been at A\&M for less than 3 years. However, $17 \%$ of those who were not aware of this service have been at TAMU for more than 7 years. See Figure 5 for the full breakdown by longevity.

Examining the respondents by user status revealed that for undergraduates, $71 \%$ of the responding freshmen were not aware of this service, followed by $61 \%$ of responding sophomores, and $43 \%$ of juniors. Looking at the total number of participating undergraduates, $51 \%$ of them were not aware of this service. Overall, undergraduates reported being the least aware user group by far as compared to other status types as noted in Table 3.

\section{Requests trend}

The yearly number of GIFM requests received from our customers has been in steady decline since 2010. This trend prompted us to ask our 


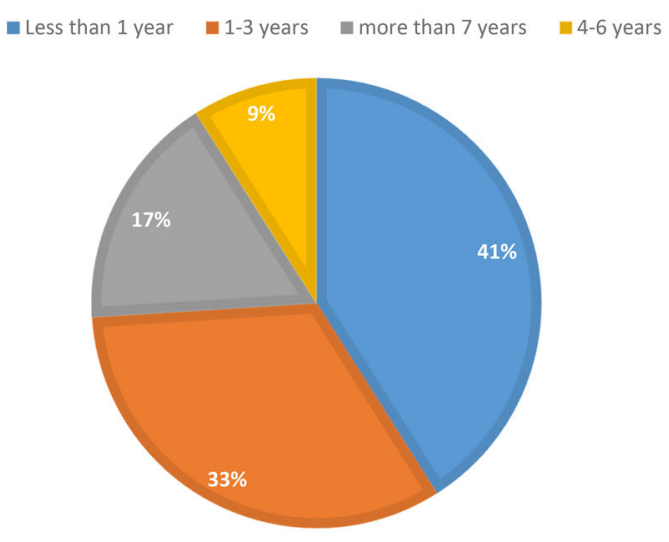

Figure 5. Respondents who were not aware of the GIFM services by longevity.

Table 3. Percentages for each user group who are unaware of the GIFM service.

\begin{tabular}{lccc}
\hline Status & $\begin{array}{c}\text { Total participants within } \\
\text { the user group }\end{array}$ & $\begin{array}{c}\text { Number of those who } \\
\text { were unaware of } \\
\text { the service }\end{array}$ & $\begin{array}{c}\text { \% of Unware of the } \\
\text { service within the group }\end{array}$ \\
\hline Undergraduate & 231 & 117 & $51 \%$ \\
Staff & 228 & 65 & $29 \%$ \\
Graduate & 293 & 74 & $25 \%$ \\
Other & 42 & 10 & $24 \%$ \\
Professor & 172 & 24 & $14 \%$ \\
\hline
\end{tabular}

survey participants if they feel that their usage of the Get It For Me service has increased, decreased, or remained the same over the last couple of years. Much to our surprise, $40 \%$ of respondents indicated that their use increased, 51\% reported that their use of the service stayed the same, and only $9 \%$ replied that they submitted fewer requests. The top two reasons respondents cited for their decrease in use of the service were "I can find most of what I need from the internet" and "I can find most of what I need from the Libraries' databases." Unfortunately, the authors did not include a similar question for respondents who reported an increase in use to better understand why they submitted more requests in the last couple of years. For those who indicated that their usage had increased, the majority or $51 \%$ were graduate students, followed by faculty members at $19 \%$. It is encouraging to note that of the responding undergraduates who have used the Get It For Me service, 31\% of them revealed that their usage had increased over the last couple of years. The leading group that indicated a decreased use of the GIFM services was faculty members, represented by $14 \%$. 


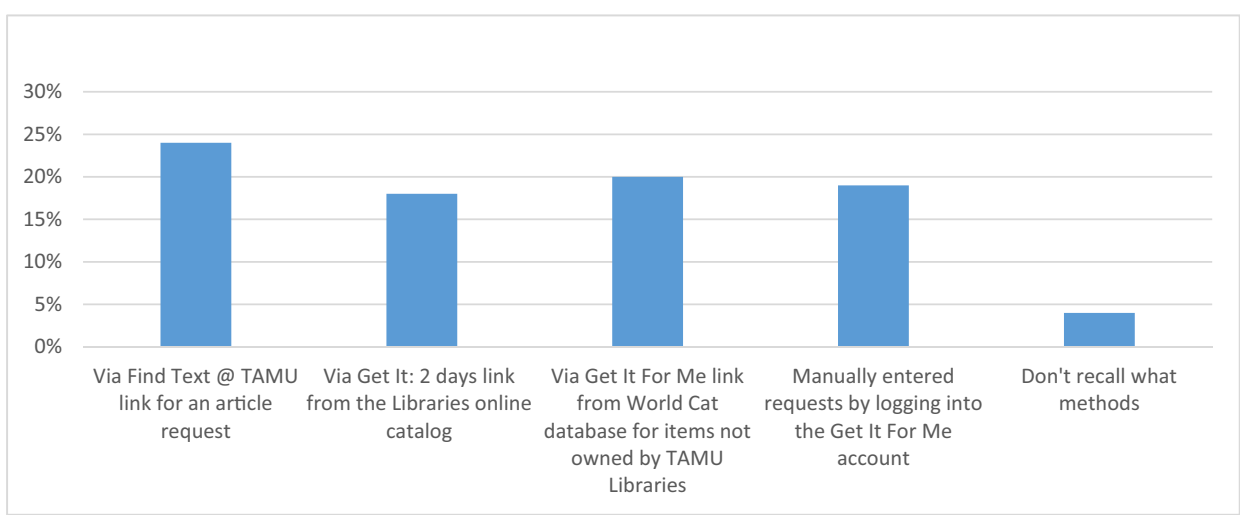

Figure 6. Methods used to submit requests to the Get It For Me service.

\section{Request submission methods}

Survey findings did not suggest any one request method for submitting GIFM requests as being dominant. As illustrated in Figure 6, submission via the SFX link for article requests take a slight lead. This could indicate that our Get It link is well placed and intuitive to our customers, after they click the link, they just sign into their account with their University NetID and password to reach a pre-populated bibliographic information request form, with a couple of required fields in need of completion (such as a not wanted after date and format preference) before they click the submit button to complete the task.

Even though almost half of the participants indicated that they had manually submitted a GIFM request, our survey findings further suggest that undergraduates are the least likely user group to manually enter a request via their GIFM account, only $18 \%$ indicated having done so compared to $67 \%$ of faculty members and $52 \%$ of graduate students.

\section{Ease of request submission}

The majority (92\%) of survey participants agreed that the Get It For Me request form is straightforward. However, we also received some constructive feedback and suggestions for improvement in this area. Several of these suggestions will be acted upon as part of the next upgrade to ILLiad 9.1 in which the request form will be modified for mobile responsiveness.

\section{Satisfaction with the delivery speed}

The overwhelming majority, about $95 \%$ of the respondents who have used the Get It For Me service, are either very satisfied or somewhat satisfied with the delivery speed of their requested items. Only $1 \%$ indicated being 
Table 4. Degree of satisfaction/dissatisfaction with the delivery speed by service function.

\begin{tabular}{lccccc}
\hline Service function & $\begin{array}{c}\text { Very } \\
\text { satisfied }\end{array}$ & $\begin{array}{c}\text { Somewhat } \\
\text { satisfied }\end{array}$ & $\begin{array}{c}\text { Neither satisfied } \\
\text { nor dissatisfied }\end{array}$ & $\begin{array}{c}\text { Somewhat } \\
\text { dissatisfied }\end{array}$ & $\begin{array}{c}\text { Very } \\
\text { dissatisfied }\end{array}$ \\
\hline $\begin{array}{l}\text { Delivery speed of } \\
\text { requested PDFs }\end{array}$ & $80 \%$ & $15 \%$ & $2 \%$ & $2 \%$ & $1 \%$ \\
$\begin{array}{c}\text { Delivery speed of requested } \\
\text { loan item owned by }\end{array}$ & $80 \%$ & $16 \%$ & $1 \%$ & $2 \%$ & $1 \%$ \\
$\begin{array}{l}\text { TAMU Libraries } \\
\text { Delivery speed of requested } \\
\text { loan item not owned by }\end{array}$ & $72 \%$ & $22 \%$ & $2 \%$ & $3 \%$ & $1 \%$ \\
TAMU Libraries & & & & & \\
\hline
\end{tabular}

very dissatisfied with the delivery speed, as demonstrated in Table 4 . When compared with the findings reported in the authors' 2012 study (Yang et al., 2012), responses from 2019 almost mirrored the previous study's findings but with even fewer respondents expressing their dissatisfaction with the delivery speed. In Yang et al.'s (2012) survey report, 79\% of the respondents said they were satisfied with the turnaround time, 18\% replied as "somewhat" satisfied with the turnaround time, and 3\% gave a flat "no." These recent findings reflect a consistency in effort across the years to deliver items as quickly and efficiently as possible.

\section{Perceived reasonable delivery time frame}

We asked all of our participants to respond to the questions regarding what they would consider a reasonable time frame for delivery based on each situation; that is, delivery of PDF items; delivery of a physical item located in TAMU Libraries; and delivery of a physical item not owned by TAMU Libraries. Under each question, we qualified with a note: our delivery speed depends on the availability of the item, and where we can get the item from. We used this opportunity to inform our users about the nuance of document delivery service; that sometimes it is out of our control.

User expectations regarding shorter PDF delivery times have increased slightly compared to Yang's (2004) report where $43 \%$ of respondents indicated a preference for receiving scanned copies within two days (Yang, 2004). In this current study, more than half (62\%) of respondents considered less than 48 hours as a reasonable expectation; to be more specific, $26 \%$ indicated the expectation for delivery within 24 hours and $36 \%$ expect delivery within 48 hours or less. Only $5 \%$ of respondents indicated having no preference as long as they can receive the article (Figure 7). Considering the speed at which people expect to access information in this electronic age, it is not at all surprising to find the demand for shorter turnaround time to be on the increase.

By comparison, when examining just TAMU Libraries respondents regarding a reasonable time frame for the delivery of PDF items, only $43 \%$, 


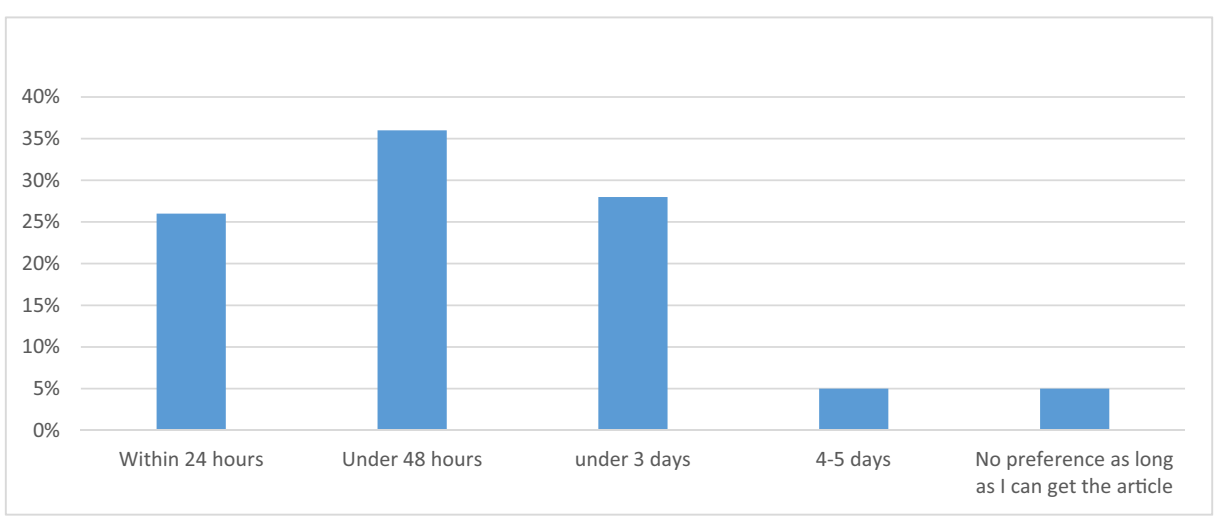

Figure 7. Reasonable time frame for delivery of PDF items.

or less than half of these individuals, considered under 48 hours as a reasonable expectation; more specifically, $15 \%$ selected within 24 hours and $28 \%$ selected under 48 hours. The majority of these respondents (51\%) indicated 3 days or less as the most reasonable time frame for PDF delivery. This is an extra 24 hours of wiggle time for delivery as compared to PDF delivery expectations across all users.

For a physical item owned by TAMU Libraries, exactly half of all respondents considered a delivery time frame of 1-2 days to be reasonable for in person pick up or to receive office delivery, 35\% indicated 3-4 days as reasonable (Figure 8).

By comparison, only $38 \%$ of TAMU Libraries respondents selected 1-2 days as reasonable with the majority of these participants (44\%) selecting 3-4 days as the optimal timeframe for delivery. This could be because they have a greater understanding of what is involved on backside to meet such a time frame.

It seems that, overall, our survey respondents understand that the delivery of items from other libraries take extra time; only $7 \%$ believe that these items should be available within 3 days. A little over half (53\%) of the respondents feel that less than 10 days is reasonable. Figure 9 details the breakdown. Responses from TAMU Libraries participants for this question are in sync with the general public.

Overall, survey responses suggest that our participants' expectations of delivery time for various items both physical and virtual, as well as inhouse and from other libraries, is reasonable and they are in line with the satisfaction rate as reported above.

\section{User discovery of the Get It for Me service}

We asked our survey participants where they learned about the Get It For Me service. One-third (34\%) of the participants indicated that they found out about the service from the Libraries' homepage, followed by $16 \%$ who 


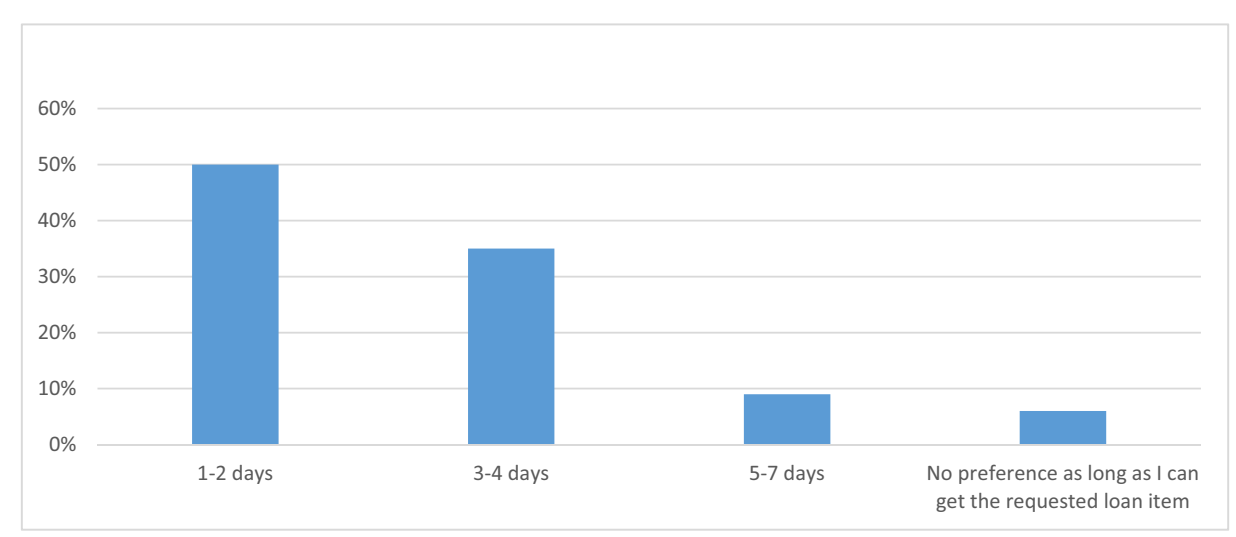

Figure 8. Reasonable time frame for delivery of TAMU Libraries item.

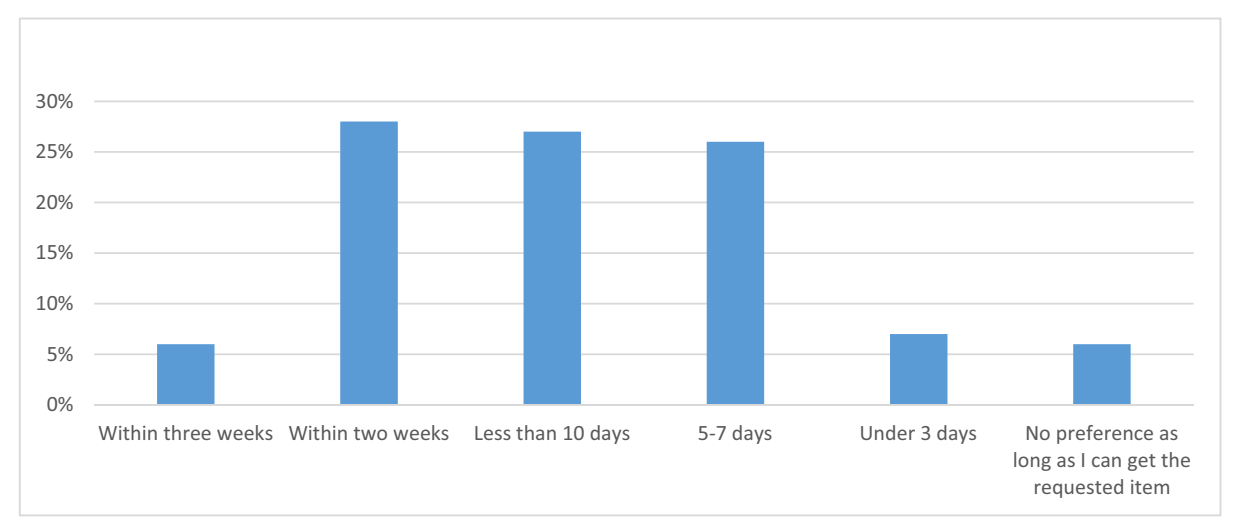

Figure 9. Reasonable time frame for items borrowed from another library.

reported a friend/colleague made them aware of the service, $9 \%$ indicated they were made aware of it from a library orientation session, $8 \%$ from their subject librarian, 7\% from their professor, and 6\% through their interactions with the AskUs desk. Additionally, others reported learning about the service from the Libraries' annual open house event (4\%), instructional classes (3\%), and as part of a library consultation session (3\%).

\section{Recommendation of the Get It for Me service to others}

Two-thirds of the participants who have used the Get It For Me service indicated they have also recommended it to others. By comparison, $91 \%$ of TAMU Libraries respondents indicated they have recommended the service to our customers.

\section{Possible future use of the Get It for Me service}

For our respondents who indicated they were not aware of the Get It For Me service prior to this survey, we asked them if they think they will create 
an account to use in the future. Of the 145 participants who responded to this question, a little over half (52\%) selected "maybe," $45 \%$ indicated "yes," and 3\%, or four participants selected "no." The reasons cited by the four participants for not wanting to use this free service echoed comments by those participants who indicated they were aware of the service but have never used it. Namely, they all indicated they do not feel that they have a need for it.

\section{Format preferences}

The Libraries' e-preferred approval plan policy has been in place since 2010. As a result, we sought to determine if our users' format preference for Get It For Me material has changed at all since our last survey in 2012 (Yang et al., 2012). Survey participants were asked, in general, if they preferred print books or ebooks. More than half (56\%) of the respondents chose print books as their preferred format. Only $16 \%$ of respondents chose ebooks, while $14 \%$ indicated they have no preference, and another $14 \%$ noted their format preference depended on certain factors: For example, several respondents shared that if they are looking for something brief or just quick information, they opt for ebooks, however, if they need to read the entire work, respondents indicated a preference for print books. Some declared ebooks to be good for travel. Many echoed that when reading for pleasure they prefer print books but when reading for work they prefer ebooks. A couple of the respondents pointed out that they like the Kindle format for ebooks because "the interface of many Libraries ebooks is sludgy and not nearly as conducive for reading as the Kindle app." When looking at responses according to participant status, $20 \%$ of faculty chose ebooks as their preferred format compared to only $15 \%$ of graduates and $13 \%$ of undergraduates. Overall, these format preference findings do not reveal any significant change since Yang et al.'s report in 2012. In the 2012 survey, the authors reported that $55 \%$ of respondents preferred print books to ebooks, only a negligible difference of $1 \%$ compared to the 2019 finding of $56 \%$.

\section{Awareness of the suggest a purchase service}

Beyond Get It For Me, we wanted to use this survey as an opportunity to assess our customers' awareness of some additional but related library services, in particular those that can be accessed or requested via one's Get It For Me account. From the survey responses, it appears that the majority $(87 \%)$ of those respondents who have used the Get It For Me service are also aware that if TAMU libraries does not own an item in the format they 
want, they can request their preferred format from another library. However, when asked if they are aware that TAMU Libraries can also purchase items other than textbooks for them via the Libraries' Suggest a Purchase link, over half (51\%) of the participants were unaware of this service. For those who are aware of this opportunity, 36\% submitted their purchase request via their Get It For Me account, with a note to ask the Libraries to purchase if the item was not available from another library; $31 \%$ submitted their purchase request directly via the Suggest a Purchase link from the Libraries' homepage; 15\% asked their library liaison/subject librarian to purchase the item for them.

\section{Article purchases}

Only a little over $10 \%$ of respondents shared that they had purchased an article themselves instead of asking the Libraries to get it for them for free. Of these individuals, the largest user population by status type who indicated they had paid for an article were graduate students $30 \%$, followed by staff (23\%), faculty (22\%), and undergraduates (15\%). Further, of these respondents, over half (58\%) indicated that they had used the Get It For Me service before and were aware they could request the item for free but elected to purchase the item themselves. For this group, graduate students still took the lead, represented by $41 \%$, followed by faculty $31 \%$, other $12 \%$, staff $8 \%$, and undergraduates $7 \%$.

\section{Top three resources to consult for information needs}

Participants were asked to choose the top three resources that they consult most often when they need information for study, teaching or research. Just as Kenefick pointed out that patrons are finding references to scholarly materials by "using search engines and not necessarily by searching through library channels" (Kenefick \& Devito, 2013), Google and Google Scholar were the top two choices selected, represented by $20 \%$ and $19 \%$, respectively, followed by the library website (17\%), library subject databases $(12 \%)$, and peers/colleagues (10\%). Figure 10 details the choices in order from the least to most consulted resources/sources. For those individuals that chose "other, please specify," Web of Science and PubMed were each mentioned as specific resources consulted by several respondents. There were a number of other responses ranging from people consulted such as "past teachers" and "professors" to other resources including two references to "eBay," other search engines such as "Bing," bibliographic resources such as "Endnote," and "Chegg" a textbook rental source. 


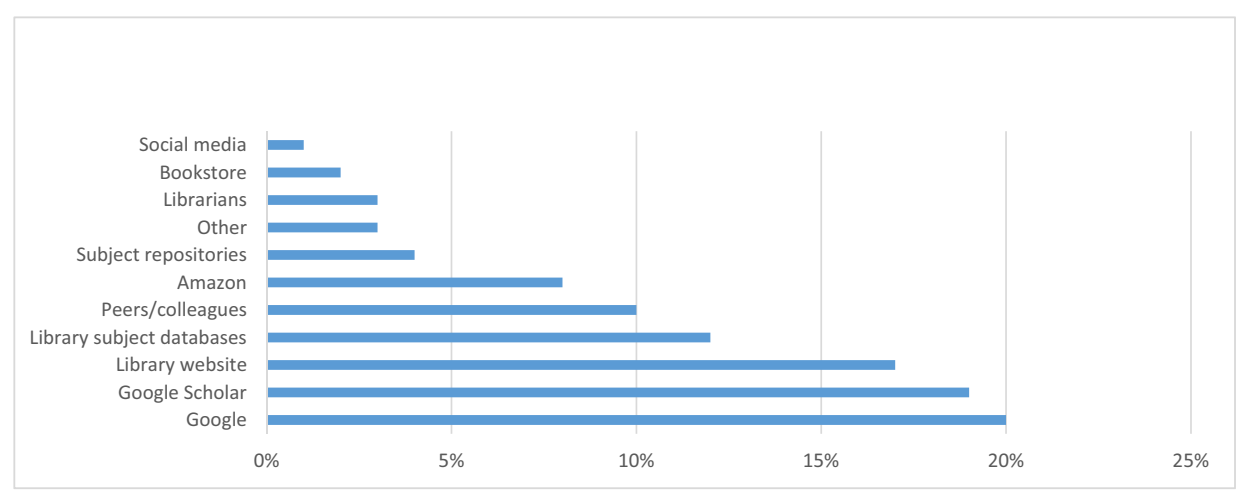

Figure 10. Top resources to consult for information needs.

It is not a surprise, that for this question, respondents from the Libraries selected the Library website $(20 \%)$ as their top choice, followed by Google (15\%), and then Google Scholar, Library subject databases, and Amazon each coming in at $14 \%$.

\section{Awareness of open access resources}

In addition to soliciting information about Get It For Me from our customers, we wanted to use this survey as an opportunity to raise and assess our customers' awareness about several quality open access resources that they can consult without having to rely strictly on the Libraries' licensed material for their information needs. We listed four resources (Digital Public Library of American, HathiTrust Digital Library, Internet Archive, and Open Access Button) with hyperlinks to their respective sites along with a brief explanation of each resource within the survey. Several participants commented that they had never heard of these resources until now and that they would check them out. Table 5 shows our respondents' awareness of each open access resource.

Among the four open access resources listed, Internet Archive seems to be known by at least one fifth of the respondents. Breaking down by respondents' status, close to one quarter of responding faculty and staff are aware of this resource, but only $15 \%$ of graduate students and $14 \%$ of undergraduates are aware of this useful site.

For this last section of the survey, we expected that survey participants from the Libraries would be much more aware of these open access resources, however, the findings revealed otherwise. While their overall awareness for each resource was higher compared to all participants, only HathiTrust reached as high as the $50 \%$ "aware of" barrier, coming in higher than the Internet Archive (42\%). Table 6 shows the detailed results for TAMU Libraries personnel. 
Table 5. Awareness of open access resources.

\begin{tabular}{lcc}
\hline Name of open access resources & Aware of & Not Aware of \\
\hline Digital Public Library of America & $10 \%$ & $90 \%$ \\
HathiTrust & $10 \%$ & $90 \%$ \\
Open Access Button & $16 \%$ & $84 \%$ \\
Internet Archive & $21 \%$ & $79 \%$ \\
\hline
\end{tabular}

Table 6. TAMU Libraries personnel awareness of open access resources.

\begin{tabular}{lcc}
\hline Name of open access resources & Aware of & Not Aware of \\
\hline Digital Public Library of America & $21 \%$ & $79 \%$ \\
HathiTrust & $50 \%$ & $50 \%$ \\
Open Access Button & $23 \%$ & $77 \%$ \\
Internet Archive & $42 \%$ & $58 \%$ \\
\hline
\end{tabular}

\section{Overall impression of the Get It for Me service}

The last survey question asked our participants if there was anything else that they would like to let us know about their experience with the Libraries or with the Get It For Me service. A total of 182 participants responded to this question, though 13 of them simply put "no" in the comment box. Participants were overwhelmingly generous about their praise for the Get It For Me service. Key words used most often to express their appreciation were awesome, valuable, fantastic, fabulous, amazing, indispensable, helpful, great, timely, prompt, and love it. Respondents recognized that this service "literally saved thousands of (dollars)" for them and they "could not live without it." For a "distance education student, this service is a LIFESAVER." Numerous respondents appreciated that we included the free open access resource websites in the survey, some indicated they bookmarked them and will "check them out." Some acknowledged that "The Get It For Me service has improved tremendously, even in the last 10 years" and "thanks for striving to improve the service." One frequent user commented: "Over a 15-year period, I have been satisfied nearly $100 \%$ of the time - and I have made hundreds of requests. Thank you for your excellent, prompt, and expert work, without which some aspects of my research and teaching would be impossible." Many thanked us for "enlightening" them on these services and resources. Some encouraged us to do "more advertising for this" service. One respondent exclaimed, "I think this should be a part of every student's experience. I have met graduate students who never knew what the library offered until I talked to them." Another wrote: "I think most undergrads are not aware of the service." Several noted that they did not know "Get It For Me was a thing," but now they "cannot wait to use it" because "this service sounds great" after taking this survey and being made aware of it.

We also received constructive suggestions such as a requestor wishing to see more detailed status reports for their individual requests and important 
notes about specific items (e.g., renewal limits). Another respondent suggested an automated tracking and alert method for checked out items when the need for a book is not time sensitive. This would save the user and the Libraries from having to request the item from another library by sending the patron an email notification once the book has been returned and is available for check out.

Other comments, perhaps influenced by popular business models included the wish for home delivery (for non-distance education users) and a couple of environmentally oriented suggestions such as, "There's a lot of packaging that seems very wasteful. Are the books really so delicate that they require a giant plastic protective pouch?" There were also some suggestions related to the required fields on the request form - specifically, requests to streamline and reconsider some of the required elements or ways to increase the ability to autofill some of the fields.

\section{Key takeaways}

\section{Delivery speeds, satisfaction and expectations}

As the findings indicated, respondents reported being overwhelmingly satisfied with delivery speeds for GIFM. A total of $95 \%$ of respondents who have used the GIFM service report being either very satisfied or somewhat satisfied with delivery speed with only $1 \%$ of respondents reporting being very dissatisfied. User expectations as to what constitutes a reasonable delivery time for PDFs has shifted slightly since the 2004 survey. In this survey, the majority of respondents (62\%) indicated 48 hours or less as the sweet spot for delivery expectations versus $43 \%$ in 2004 . It is also interesting to note that library personnel who answered this question tended to be less demanding regarding PDF delivery times, with over half (51\%) indicating a 3-day window versus 2-day window as reasonable.

Despite a slight uptick in shorter delivery time expectations for PDF delivery compared to earlier surveys, patron satisfaction for those that have reported using the service continues to remain high in tandem with our ability to provide fast and efficient service delivery. We continue to look for ways to streamline our delivery process and proactively communicate with our patrons about what to expect with regards to delivery time to help manage expectations up-front (e.g., indicating on request buttons average delivery time). These measures allow our customers to make informed and timely decisions about when to use GIFM for their information needs or opt to find other means. While there is evidence that some users are willing to pay for materials even when they know they can get it for free through GIFM, the choice to pay does not appear to be a reflection of any negative experience with GIFM or an indication that individuals will no 
longer use GIFM for future information needs. As noted in the results section, over two-thirds of respondents who have used GIFM have also recommended it to their colleagues.

\section{Usage, awareness, and marketing}

While we have seen a continuing decline in the number of new user registrants since 2010 , with only $11 \%$ of the campus population registered for Get It For Me, 91\% of survey respondents who have an account and use the GIFM service indicated their use of the service has either increased $(40 \%)$ or remained the same $(51 \%)$ over the last couple of years. The top two reasons why the remaining $9 \%$ of respondents indicated a decline in use was due to the ability to find everything they need online or via the library website. Unfortunately, these numbers do not tell us anything about why there has not been a similar overall steady or upward trend in terms of new user registrations. It is interesting to find that while the overall use of the GIFM service of current registered users has remained consistent or increased, overall registrations have been on the decline. Knowing that $97 \%$ of survey respondents who indicated they were not aware of the GIFM service prior to the survey and indicated that they would now either create an account $(45 \%)$ or maybe create an account $(52 \%)$ indicates the value of our continued efforts to spread the word about the benefits of Get It For Me to the campus community. Clearly, once individuals understand what the service can do for them, almost half indicate they will take advantage of it and the other half indicate a willingness to consider signing up. In addition to targeted marketing, it appears that future surveys about GIFM to the entire campus community, rather than just registered users, is a valuable way to help raise additional awareness about this service. The authors were particularly happy with the large response rate and the number of non-registered and non-aware users who willingly took the time to provide their perspectives.

Survey results about how users interact and access GIFM services indicate that users equally take advantage of the variety of ways in which we provide access points across our web ecosystem and other third party ecosystems, in addition to manual entry requests within one's GIFM account page, to ensure ease of access and the possibility of point of need requests. We continue to look for ways to embed the link to Find Text @ TAMU for article requests wherever possible as we discover new free online search platforms and information tools, as well as purchase new online databases and information resources.

When it comes to fostering successful, high-use, and much loved library services like Get It For Me, it really does take a village: It is clear from our 
survey results that across all user types, people have become aware of GIFM services through a variety of means including creative marketing campaigns, bulk emails, online integration with other resources and services, active publicity at different library events and venues, and thanks to word of mouth publicity from various library service providers outside of the Interlibrary Loan department. Public services staff from subject librarians and liaisons to instructional services librarian to frontline staff at service desks have all played a pivotal role in spreading the word out about GIFM as part of their daily interactions with patrons. Respondents also noted a variety of Libraries-wide outreach and instruction events in which they learned about GIFM, such as our annual Open House event. It is heartening to see that our marketing efforts to insert specific information about core services such as GIFM at large scale events are making an impact. New faculty orientations and tours, graduate student orientations and theses/dissertation bootcamps are also key venues in which the TAMU Libraries actively publicize this core resource to students and faculty.

It is worth noting that all these events and venues except annual Open House event are ones in which one does not typically find interlibrary loan staff participating due to their behind the scene nature of work. This is why it is so important for Interlibrary Loan departments to collaborate closely with other partners across the library in addition to marketing units (if they exist) to get the word out about the service. Proactively sharing the results of these types of service/department-based surveys with staff from across the library is also important. In particular, it is beneficial to let public service staff know that their day to day work, sharing information with patrons about core library services like GIFM, has a direct impact on future patron behavior and information choices once they make them aware of all the library has to offer regardless of whether the message is shared at a service desks, outreach event, research consultation, or instruction session. Clearly, based on the variety of ways in which respondents indicated they learned about GIFM, there is no single "right" way to market this service. The more ways to get the word out, the better. As Schmidt eloquently penned that "Libraries have a responsibility to contribute to the growth of an educated literate society and to ensure that their services are well-known and well-used. Libraries must promote themselves effectively" (Schmidt, 2007).

\section{What is next for TAMU Libraries and its Get It for Me service?}

As noted in the findings section, there are a couple of respondent suggestions for enhancements and bug fixes. We have already acted on these requests to enhance our services for our customers. For example, one 
patron let us know that if they forget to fill out a required field and hit "submit" in the request form, the form deletes optional information added to the form. However, we could not duplicate the issue. We believe this issue was a glitch and was resolved by itself. Another participant made an excellent suggestion that he would like to see an alert link whenever the book has been returned so that customers don't have to use the GIFM option to request the item from another library, since they are not in a hurry to receive it. Our current Voyager circulation system does not have this alert link capability. However, with the prompting of this suggestion, we can add a question in the GIFM request form: "If the requested book is checked out, do you want us to request it from another library or notify you when it is returned?" We will make it a required field for them to choose one of the two options. If they choose to be notified instead of to borrow immediately, staff will create a hold record in Voyager so that the customer will be notified once the book is returned. TAMU Libraries are in the process of switching our Integrated Library System from Voyager to FOLIO, an open source app based Library System Platform, this excellent suggestion has also been forwarded to the developers for consideration.

Another theme that emerged from the comments was around environmental considerations regarding our delivery service and the use of plastic packaging to protect materials and plastic slip covers to help patrons and staff distinguish interlibrary loan material (non-TAMU items) from TAMU-owned items. We will explore options for greater sustainability in support of a university-wide Sustainability Master Plan while balancing the need to ensure materials are not damaged in transport and paperwork from lending libraries are intact.

It is no surprise that respondents identified Google and Google Scholar as the top information resources they consult for their information needs, with the library website coming in a close third. Libraries cannot afford to be complacent about such results. Despite being two points shy of Google Scholar in second place, Libraries must continue to find ways to seamlessly integrate relevant collections and services where possible with third party products and search platforms like Google to ensure patrons are able to discover relevant library resources at point of need regardless of whether they choose to start their search on a library website, vendor database, online book seller like Amazon, or search engine.

Finally, it is important to note that periodic assessment of our services is a necessity to ensure continued success but equally important is the need to periodically remind our customers of the library services available to them. Our customers appreciate our marketing effort, as one survey participant wrote in our last open ended question: "I appreciate knowing that if needed the libraries are such a source of wealth and knowledge." As Smith 
nicely put: "Whether physical or virtual, an academic library's collection and services are relevant only to the extent that they are used by their intended audience" (Smith, 2011).

\section{ORCID}

Zheng Ye (Lan) Yang (D) http://orcid.org/0000-0001-6757-7822

\section{References}

Atwater-Singer, M. (2011). Interlibrary loan satisfaction survey at the University of Evansville. Journal of Interlibrary Loan, Document Delivery \& Electronic Reserve, 21(5), 227-233. doi:10.1080/1072303X.2011.635842

D’Elia, G., \& Hutkins, C. (1986). Faculty use of document delivery services: The results of a survey. Journal of Academic Librarianship, 12(2), 69-74.

Del Bosque, D., Mitola, R., Skarl, S., Heaton, S., et al. (2017). Beyond awareness: Improving outreach and marketing through user surveys. Reference Services Review, 45(1), 4-17. doi:10.1108/RSR-02-2016-0009

Fong, Y. S. (1997). The value of interlibrary loan. Journal of Library Administration, 23(12), 43-54. doi:10.1300/J111v23n01_04

Frank, P. P., \& Bothmann, R. L. (2008). Assessing undergraduate interlibrary loan use. Journal of Interlibrary Loan, Document Delivery \& Electronic Reserve, 18(1), 33-47. doi: 10.1300/J474v18n01_05

Herrera, G. (2003). Interlibrary loan user behaviors in an academic library. Journal of Interlibrary Loan, Document Delivery and Information Supply, 14(2), 19-36. doi:10.1300/ J110v14n02_03

Jong, C. J., \& Nance, H. (2014). In a world of Amazon, is it time to rethink ILL? Interlending \& Document Supply, 42(2/3), 42-50. doi:10.1108/ILDS-02-2014-0019

Kenefick, C., \& Devito, J. A. (2013). Google expectations and interlibrary loan: Can we ever be fast enough? Journal of Interlibrary Loan, Document Delivery \& Electronic Reserve, 23(3), 157-163. doi:10.1080/1072303X.2013.856365

Landes, S. (2001). Interlibrary loan survey: State University of New York College at Geneseo libraries. Journal of Interlibrary Loan, Document Delivery \& Electronic Reserve, 11(4), 75-80. doi:10.1300/J110v11n04_06

Leykam, A. (2008). Exploring interlibrary loan usage patterns and liaison activities: The experience at a US university. Interlending \& Document Supply, 36(4), 218-224. doi:10. $1108 / 02641610810919570$

Little, M., \& Leon, L. (2015). Assessing the value of ILL to our users: A comparative study of three US libraries. Interlending \& Document Supply, 43(1), 34-40. doi:10.1108/ILDS-10-2014-0051

Lucas, D. (2011). Faculty in-service: How to boost academic library services. Collaborative Librarianship, 3(2), 117-122.

Mak, C. (2012). Add to cart? E-commerce, self-service and the growth of interlibrary loan. Interlending \& Document Supply, 40(1), 26-30. doi:10.1108/02641611211214251

McGrath, M. (2012). A global perspective on ILL: Is it in good health and will it survive? Insights: The UKSG Journal, 25(1), 80-85. doi:10.1629/2048-7754.25.1.80

Muhonen, A., \& Saarti, J. (2016). The changing paradigm of document delivery-Exploring researchers' peer to peer practices. Interlending \& Document Supply, 44(2), 66-71. doi:10. 1108/ILDS-02-2016-0006 
Naylor, T. E., \& Wolfe, J. A. (2008). Interlibrary loan patron satisfaction at the Wichita State University libraries. Journal of Interlibrary Loan, Document Delivery \& Electronic Reserve, 18(3), 347-374. doi:10.1080/10723030802186371

Perrault, A. H., \& Arseneau, M. (1995). User satisfaction and interlibrary loan service: A study at Louisiana State University. RQ, 35(1), 90-100.

Schmidt, J. (2007). Promoting library services in a google world. Library Management, 28(6/7), 337-346. doi:10.1108/01435120710774477

Smith, D. A. (2011). Strategic marketing of library resources and services. College \& Undergraduate Libraries, 18(4), 333-349. doi:10.1080/10691316.2011.624937

Yang, Z. Y. (2004). Customer satisfaction with interlibrary loan service - deliverEdocs: A case study. Journal of Interlibrary Loan, Document Delivery \& Electronic Reserve, 14(4), 79-94. doi:10.1300/J110v14n04_07

Yang, Z. Y. (2005). Providing free document delivery services to a campus of 48,000 library users. Journal of Interlibrary Loan, Document Delivery \& Electronic Reserve, 15(4), 49-55. doi:10.1300/J474v15n04_05

Yang, Z. Y., Hahn, D., \& Thornton, E. (2012). Meeting our customers' expectations: A follow-up customer satisfaction survey after 10 years of free document delivery and interlibrary loan services at Texas A\&M University Libraries. Journal of Interlibrary Loan, Document Delivery \& Electronic Reserve, 22(2), 95-110. doi:10.1080/1072303X.2012. 708390 